pebbles set on end, those larger stones suspended in what was once a plastic mud, that distinct line of demarcation between the moved and unmoved ground usually marked with slikenside if you look for it, those beds bent back and dragged down hill-nay, sometimes bent over on level ground : all these are indications of some universal agency, bringing the surface into the state in which we see it. What power was competent to produce, not one of, but all these effects?

The modern changes in the form of the ground, by the growth of peat, the silting up of valleys, the erosion of the banks of streams, the slipping of hill-sides under the action of springs, will help the close student of the subject to arrive at a satisfactory conclusion upon the older mode of denudation; for they will show him that the present agency of rain, and rivers, and springs, is modifying, not continuing to produce, the original contour of the ground. Until all these indications of form and condition of the surface are patiently and honestly studied, this question will continue to vex the geological mind, and to occupy the valuable pages of your Magazine.

\title{
Hariton, Cambridge.
}

O. Fisher.

P.S.-The above was written before the appearance of the December number of the Magazine, and has no reference to the papers therein contained.

\section{THE EARTH'S FEATURES,}

SIR,- "The true views of the operations of nature in sculpturing the surface of the earth can never be arrived at unless we take into consideration the effects of all possible agencies, and give them their due place in the great work." 1

Never were truer words spoken than the above,-Marinists may rave about what their special agent can do ; so may Subaërialists proper, Glacialists, and every other ists, but unprejudiced observers will find that all the different agencies work hand in hand, and that if any of them had been absent, the present features of the earth could not have been formed as we now find them.

Why is it necessary that any new theory should be invented or any special theory adopted to account for the present features of the Earth? Why not rather allow the existing forces to do the work nature has assigned each? Let the changes in the earth be considered from "the beginning," and may not a solution for most, if not for all, the apparent difficulties be found? To suit the special theories, various forms have been suggested as the first; but is there one of them so simple or better than that given in THE Boor-" The earth was without form and void, and the spirit of God moved on the face of the water." From this, the oldest record, it would appear that at " the beginning," the earth was surrounded by an envelope of water. Moreover, this statement agrees with present conditions; for a similar phenomenon might again occur if all the land was sunk in the depths of the ocean. This sea, as proved by Mr. Campbell in "Frost and Fire," must have been motionless, there being no light

\footnotetext{
1 Hull, “Gror. Mag.” Vol. IV. p. 669.
} 
-when light was created, motion began, and after that, "the dry land appeared,"-since then there has been perpetual motion, during which, parts of the land have been submerged, while other parts have been elevated; and this process has been enacted over and over again. While the land was above the sea, "Frost and Fire," with "Rain and Rivers," have each in their appointed place done their work; neither was the sea idle, as it must have acted on the land as it was appearing above, or disappearing under the waters, carving out the main features afterwards to be remodelled by the other existing forces.

An observer who has seen the sea yearly carrying away a coast may be inclined to believe that it is the great destroyer; while those who live among soft strata that are easily denuded, may pin their faith to "Rain and Rivers," and those accustomed to Alpine or Arctic regions to ice; but an unprejudiced observer will find that "all are right and all are wrong." Moreover, if the advice of the Chameleon-

\section{"When next you talk of what you view,} Think others see as well as you,"

was generally adopted among geologists, it would not be so difficult a task as at present to find "keys to fit all the locks."

The Biblical record may be sneered at because human remains have not been found except among the most recent of the Tertiary deposits. However, in answer to this I may be allowed to put forward Col. Greenwood's suggestion; that there is only negative evidence against the existence of Man and the other land animals from the earliest perions of the earth; for to quote that author's words :L" "Where are the fossil remains of land quadrupeds found? In cavern deposits, in drift and alluvium 'deposited on dry land,' in filled up lakes, in bogs, or frozen up in polar regions. Now all these land museums are not only modern, but they are superficial and temporary. They are liable to be washed into the sea; and their fossil contents must be destroyed before they can be re-deposited in marine strata."

Connemara, Dec. 1st, 1867.

G. Henkey Kinahan.

\section{DENUDATION OF THE WEALD.}

Sir,-In your December number, page 572, Mr. Mackintosh names me as "Colonel Greenwood, the father of modern subaërialism." And thereupon he puts this question to me, "If rain has washed away the soluble chalk, what has become of the insoluble flints ?" In reply I would ask Mr. Mackintosh where do "surface flints" come from? I have said "Everything on the surface of the earth which is not living is decaying. On this decay depends soil. On soil, vegetable life. On vegetable life, herbivorous animals. On herbivorous animals, carnivorous animals. So that all life depends on decay." At page 211, of "Rain and Rivers," is this passage,"In chalk countries denudation leaves a residuum of flints on the surface, because though these flints disintegrate and though each is 1 "Rain and Rivers" 2nd Edition. p. 199. 